\title{
CURSO TÉCNICO DE ENFERMAGEM DO PROFAE-CEARÁ: A VOZ DOS SUPERVISORES ${ }^{1}$ NURSING ASSISTANT COURSE IN PROFAE-CEARÁ: THE SUPERVISORS' VOICE CURSO TÉCNICO DE ENFERMERÍA DEL PROFAE-CEARÁ: LA VOZ DE LOS SUPERVISORES
}

\author{
Carmem Cemires Cavalcante Costa², José Gomes Bezerra Filho ${ }^{3}$, Márcia Maria Tavares Machado \\ Maria de Fátima Antero Sousa Machado ${ }^{5}$, Antônia Cristina Jorge ${ }^{6}$, Ana Adelaide Américo Furtado ${ }^{7}$, \\ Ivina Maria Siqueira Lima ${ }^{8}$
}

\footnotetext{
${ }^{1}$ Pesquisa financiada pelo Programa de Incentivo à Pesquisa nas Escolas Técnicas do Sistema Único de Saúde no âmbito do Projeto de Profissionalização dos Trabalhadores da Área de Enfermagem/Ministério da Saúde/Organização das Nações Unidas para a educação, a ciência e a cultura.

${ }^{2}$ Mestre em Saúde Pública Coordenadora de projetos de educação profissional técnica de nível médio da Escola de Saúde Pública do Ceará (ESP-Ceará). Ceará, Brasil.

${ }^{3}$ Doutor em Saúde Coletiva. Professor Adjunto do Departamento de Saúde Comunitária da Faculdade de Medicina da Universidade Federal do Ceará (DSC/UFC). Ceará, Brasil.

${ }^{4}$ Doutora em Enfermagem em Saúde Comunitária. Professor Adjunto do DSC/UFC. Ceará, Brasil.

${ }^{5}$ Doutora em Enfermagem. Professora do Curso de Enfermagem da Universidade Regional do Cariri, da Universidade de Fortaleza e da ESP-Ceará. Ceará, Brasil.

${ }^{6}$ Mestranda em Saúde Pública do DSC/UFC. Ceará, Brasil.

${ }^{7}$ Especialista em Formação Pedagógica na área da saúde: Enfermagem, Instituto Dr. José Frota. Ceará, Brasil.

${ }^{8}$ Mestranda em Avaliação de Políticas Públicas pela Universidade Estadual do Ceará. Ceará, Brasil.
}

PALAVRAS-CHAVE: Avaliação. Educação em enfermagem. Políticas públicas.

KEYWORDS: Evaluation. Education, nursing. Public policies.

PALABRAS CLAVE: Evaluación. Educación en enfermería. Políticas públicas.
RESUMO: Estudo qualitativo cujo objetivo foi analisar o Curso Técnico de Enfermagem da Escola de Saúde Pública do Ceará, realizado no âmbito do Projeto de Profissionalização dos Trabalhadores da Área de Enfermagem, na visão dos enfermeiros supervisores, vislumbrando conhecer os pontos fortes e dificuldades enfrentadas. Realizou-se um grupo focal com 10 supervisores do curso, em fevereiro de 2007. A análise de conteúdo das falas evidenciou que o curso possibilitou o desenvolvimento de competências para o técnico de enfermagem. Entre os pontos positivos, destacaram-se a utilização da metodologia da Problematização e a qualidade do material didático. As dificuldades apontadas referem-se à logística do curso, ressaltando o pouco apoio da gestão municipal e a limitação dos campos de estágio. Concluise, portanto, que essa estratégia educacional deve ser pautada na educação permanente, como forma efetiva de assegurar reflexão e mudanças significativas nos processos de trabalho em saúde.

ABSTRACT: The objective of this qualitative study was to analyze the Technical Nursing Course of the Ceará School of Public Health (Brazil), made possible by the Professionalization Project of Nursing Workers, from the view of supervising nurses in order to know the course's strengths and weaknesses. A focus group made up of 10 course supervisors was carried out in February of 2007. Discourse content analysis made evident that the course allowed for nursing technical competency development. The problematization methodology and the quality of the teaching-learning resources were among its positive aspects. The main difficulties pointed out were related to the course logistics, the lack of municipal support, and limited internship opportunities. We conclude, however, that this educational strategy must be implemented into permanent education as an effective way to ensure professional reflection and significant changes in health care work processes.

RESUMEN: Estudio de carácter cualitativo, cuyo objetivo fue analizar desde la óptica de los enfermeros supervisores, el Curso Técnico de Enfermería de la Escuela de Salud Pública de Ceará, realizado en el ámbito del Proyecto de Profesionalización de los Trabajadores del Área de Enfermería, para conocer los puntos fuertes y las dificultades enfrentadas. Se organizó un grupo focal con 10 supervisores del curso, en febrero de 2007. El análisis de contenido de las declaraciones evidenció que el curso posibilitó el desarrollo de competencias para el técnico de enfermería. Entre los puntos positivos, se destacaron: la utilización de la metodología de la Problematización y la calidad del material didáctico. Las dificultades indicadas se refieren a la logística del curso, resaltando el escaso apoyo de la gestión municipal y la limitación de los campos de prácticas. Se concluye, por lo tanto, que esta estrategia educacional debe ser colocada en la pauta de la educación permanente, como forma efectiva de propiciar la reflexión y cambios significativos en los procesos de trabajo en salud.
Carmem Cemires Cavalcante Costa

Endereço: Avenida Antônio Justa, 3161

60165-090 - Meireles, Fortaleza, CE, Brasil

E-mail: carmem@esp.ce.gov.br
Artigo original: Pesquisa

Recebido em: 15 de abril de 2008

Aprovação final: 14 de outubro de 2008 


\section{INTRODUÇÃO}

O Projeto de Profissionalização dos Trabalhadores da Área de Enfermagem (PROFAE) foi criado pelo Ministério da Saúde (MS), tendo como objetivo qualificar profissionalmente os trabalhadores da área de Enfermagem e, conseqüentemente, melhorar a qualidade dos serviços de saúde públicos e privados. Suas atividades tiveram início em 2000, estendendo-se por quatro anos. A meta principal era a qualificação de 225.000 trabalhadores que atuavam sem habilitação para o exercício profissional, na época, representando cerca de $30 \%$ dos trabalhadores do País. ${ }^{1}$

Outra meta prioritária do projeto incluía o Curso de Complementação da Qualificação Profissional de Auxiliar de Enfermagem para Técnico em Enfermagem, destinado aos auxiliares com ensino médio concluído, que estivessem empregados em estabelecimentos de saúde de média e alta complexidade. ${ }^{2}$

A Escola de Saúde Pública do Ceará (ESP$\mathrm{CE}$ ), operadora e executora dos cursos do PROFAE no Estado, qualificou 5.351 auxiliares de enfermagem e 797 técnicos de enfermagem, entre os anos de 2001 a 2005. * Esse processo foi realizado em consonância com a normatização da Lei de Diretrizes e Bases, implementando os cursos por meio de um currículo norteado nas competências do exercício profissional, sendo pautado nos princípios do Sistema Único de Saúde (SUS).

O corpo técnico-pedagógico do Curso Técnico de Enfermagem (CTE) era constituído por um coordenador geral, uma equipe de coordenadores pedagógicos e locais, facilitadores e supervisores de estágio. O coordenador pedagógico era responsável pela coordenação técnico-pedagógica na execução das turmas, no sentido de acompanhar, avaliar e apoiar o desempenho dos coordenadores locais, facilitadores e supervisores de estágio, aplicando os mecanismos pertinentes para o aprimoramento e o desenvolvimento profissional.

Na operacionalização das turmas do PROFAE/ESP-CE, o supervisor atuava no ensinoaprendizagem, sendo responsável por uma turma de 12 a 15 alunos, acompanhando-os nos momentos de concentração (teoria e prática) e dispersão (estágio), de acordo com a metodologia da Problematização, que tem como estratégia operacional o trabalho em pequenos grupos.
Diante de um objetivo tão ousado, de melhoria da qualidade da atenção à saúde, devendo ser assegurada, dentre outros fatores, por uma educação profissional efetiva, várias reflexões surgiram no âmbito da instituição formadora acerca da adequação do CTE ofertado à clientela do PROFAE, no que diz respeito à organização curricular, à metodologia, aos conteúdos ministrados e aplicação prática dos conhecimentos apreendidos.

Essas reflexões tomam corpo por meio deste estudo, quando se propõe analisar o CTE na visão dos supervisores, atores ativos desse processo, vislumbrando um reconhecimento dos pontos fortes, bem como das dificuldades decorrentes no seu desenvolvimento, compreendendo que este processo ensejará um redirecionamento de futuros cursos técnicos na área de enfermagem, no estado e no cenário nacional.

\section{METODOLOGIA}

Este estudo faz parte de um projeto financiado pela Organização das Nações Unidas para a educação, a ciência e a cultura - UNESCO, em parceria com o MS, por meio da Secretaria de Gestão do Trabalho e da Educação na Saúde, intitulado "Avaliação do Curso Técnico em Enfermagem/ PROFAE pelos egressos e supervisores no Estado do Ceará", compreendendo o resultado da primeira etapa desse projeto. Foi aprovado pelo Comitê de Ética em Pesquisa da ESP-CE, sob o Parecer $N^{\circ}$ 04/2006, seguindo o preconizado pelo Conselho Nacional de Saúde, MS, Brasil.

Trata-se de um estudo descritivo-exploratório, de natureza qualitativa, optando-se por essa metodologia pelo fato de se reconhecer a existência de uma relação dinâmica entre o mundo real e o sujeito, por trabalhar com o universo de significados, valores e atitudes dos processos e fenômenos, respondendo, portanto, às questões norteadoras deste estudo. ${ }^{3}$

O estudo teve início com a identificação dos enfermeiros que atuaram como supervisores do CTE, no período de 2002 a 2005, através do banco de dados da Unidade de Escrituração Escolar da ESP-CE. Em seguida, realizou-se o primeiro contato telefônico com as secretarias municipais de saúde para identificar os supervisores que ainda trabalhavam nesses municípios, adotando como critério de seleção a permanência no município

\footnotetext{
* Equipe Técnica (PROFAE/ESP-CE). Relatório de conclusão dos cursos de qualificação profissional em auxiliar de enfermagem e de formação técnica em enfermagem. Ceará: Escola de Saúde Pública do Ceará; 2005
} 
desde o período de atuação como supervisor dos cursos do PROFAE.

Para assegurar, na medida do possível, um número representativo de participantes, buscouse contato com supervisores de regiões diferentes do Ceará, realizando um cadastramento prévio daqueles que atendessem aos critérios e que demonstrassem interesse e disponibilidade em participar voluntariamente do estudo.

Os dados foram coletados através da realização de um Grupo Focal (GF), sediado no município de Fortaleza, em fevereiro de 2007, contando com a presença de dez enfermeiros, dos doze que se disponibilizaram inicialmente em participar do estudo. Na utilização do GF, observou-se o rigor de que trata a literatura, no que se refere à homogeneidade do grupo (todos os participantes eram supervisores), ao limite de participantes que pudesse proporcionar boa interação e condução pelos facilitadores e moderadores, bem como a utilização de um roteiro para direcionar a discussão. ${ }^{4}$

Para desenvolvimento do GF, foi elaborado um roteiro semi-estruturado explorando questões relacionadas à percepção dos supervisores acerca do CTE, destacando os pontos fortes e as dificuldades enfrentadas no decorrer do processo formativo. Utilizou-se como pergunta norteadora central a seguinte, introduzida no início do GF: “O que vocês acharam do CTE do PROFAE, no que se refere à organização, conteúdo e metodologia?".

Optou-se por utilizar a gravação das falas provenientes das discussões, após o consentimento dos participantes, mediante assinatura do Termo de Consentimento Livre e Esclarecido, e transcrevê-las, fidedignamente, para análise posterior, respeitando o sigilo do nome e das informações fornecidas. Buscou-se, portanto, obter informações suficientes para a reconstituição do universo simbólico dos informantes, de modo a permitir uma análise aprofundada das falas, envolvendo o ponto central do tema em estudo.

Essa técnica de entrevista contribuiu com a coleta de dados, pois esse tipo de instrumento propicia o relato de experiências e percepções em torno de um tema, obtendo informações qualitativas em profundidade. O sucesso no uso da técnica está no fato de que deve existir um foco central, um tópico a ser explorado, que pode ser um tema específico, um grupo, ou ambos. ${ }^{5}$

Após a transcrição das fitas, na forma íntegra do uso da palavra dos supervisores, procedeu-se à leitura flutuante e aprofundada das falas, com formulação de categorias, utilizando-se a análise de conteúdo, ${ }^{6}$ com suporte em um diálogo aproximado com a literatura revisada para a pesquisa. Ao término dessa etapa, julgou-se haver acessado o material focalizado na investigação, cuja categorização realizada na etapa de processamento e análise indicou uma convergência das categorias em torno de dois temas centrais, sobre os quais se passa a discorrer.

\section{RESULTADOS E DISCUSSÃO}

\section{Caracterização dos informantes}

O estudo contou com a participação de 10 supervisores, com idade entre 24 e 56 anos e tempo médio de formação de 12 anos. Todos os enfermeiros tinham pós-graduação na área da saúde em nível de especialização (Saúde da Família, Saúde Pública, Enfermagem Médico-Cirúrgica etc.). Como formação complementar, todos os entrevistados também concluíram a especialização em Formação Pedagógica na Área de Saúde ofertada pelo PROFAE a todos os enfermeiros-docentes do projeto.

Os supervisores estavam atuando na área administrativa (cinco), em unidades hospitalares (quatro) e apenas um trabalhava na Estratégia Saúde da Família, no momento de realização do grupo focal.

Os participantes haviam sido responsáveis por turmas de Técnico de Enfermagem que ocorreram nos anos de 2002 (dois), 2003 (um), 2004 (cinco) e 2005 (dois). Alguns deles (quatro) haviam supervisionado também turmas de Auxiliar de Enfermagem do PROFAE, em períodos distintos.

A seguir, são apresentadas as categorias apreendidas com base nas falas dos supervisores.

\section{Mudanças advindas com o Curso Técnico de Enfermagem/PROFAE}

Conforme os supervisores, o CTE/PROFAE, realizado em parceria com a ESP-CE, ofereceu boa estrutura em termos organizacionais, desde a capacitação dos docentes, a operacionalização e a organização curricular.

$\mathrm{Na}$ visão dos enfermeiros, o curso possibilitou uma atualização dos auxiliares de enfermagem, no que se refere ao conhecimento da área, as habilidades para desenvolver os procedimentos e as atitudes frente às diversas situações de saúdedoença, fazendo do curso um instrumento gerador de competências para o técnico de enfermagem. 
Os supervisores acrescentaram, ainda, que o curso motivou os discentes na busca contínua de conhecimento, na reflexão sobre sua prática cotidiana, porquanto muitos, embora já trabalhassem na área de saúde, haviam perdido o estímulo para a busca permanente do seu aprendizado, seja pela carga horária excessiva de trabalho, acomodação, falta de hábito de leitura, dentre outros. Estes fatos estão expressos nos depoimentos dos sujeitos que participaram do grupo focal.

Com relação à atualização dos profissionais, eles até referiram no decorrer do curso que foi muito bom pra eles porque funcionou como uma revisão, porque há muito tempo eles não pegavam nada pra estudar e até por falta de tempo ou por acomodação e assim funcionou pra dá uma sacudida (S3).

[...] foi uma forma de melhorar a qualidade deles em relação à prática e ao próprio aprendizado, porque alguns como já estavam na área há algum tempo ficam meio enferrujados, tem preguiça de ler (S8).

As atividades propiciaram aos alunos uma reflexão sobre o fazer da enfermagem, integrando a prática e a teoria, por meio da discussão de procedimentos e técnicas adequados, o que contribuiu para um novo despertar dos alunos acerca do seu saber-fazer-ser. Os depoimentos em seguida refletem essa realidade.

Nós tínhamos quase 99,98\% de auxiliares atuantes dentro do hospital, então assim, uma coisa que chamava muito a atenção da gente era a questão do repasse do que eles faziam no dia-a-dia, pois naquele momento de atuação eles achavam que não tinha a mínima importância o que eles estavam fazendo (S2).

[...] a cada dia acho que a gente dava o estímulo e eles passaram a questionar, a não aceitar mais as coisas como elas eram. Tipo assim: será que esse atendimento que tá sendo feito no hospital ou no próprio posto de saúde tá correto? (S10).

Considerando que os candidatos ao CTE do PROFAE/ESP-CE já trabalhavam na área de enfermagem, a proposta de formação estava pautada na educação permanente. O conteúdo das diversas disciplinas era desenvolvido de maneira articulada e em estreita relação com a prática, conduzindo o aluno desde as ações de menor às de maior complexidade.

Esta motivação e o despertar para a autoreflexão sobre a prática podem estar relacionados com a metodologia adotada no curso. De acordo com os supervisores, há uma compreensão de que a Problematização auxiliou no aprendizado, despertando o interesse dos alunos pelo curso, bem como a atualização dos conhecimentos. Os depoimentos a seguir retratam esta situação.

Eu acho que a grande diferença está na metodologia, porque o aluno é acostumado antigamente no ensino a receber, e nesse curso do PROFAE, através da problematização, ele começou a andar com as próprias pernas, ele despertou (S7).

A gente ajudava, mas eles que iam construindo à vontade todo o conhecimento, então depois dali eles viram que podiam continuar, acho que ficou a pulguinha atrás da orelha de estar sempre lendo, procurando alguma coisa [...] (S1).

A formação de profissionais críticos e reflexivos, com capacidade de enfrentamento dos problemas que se apresentam na sociedade e, principalmente, na área da saúde, implica a utilização de metodologias ativas de ensino-aprendizagem, que permitam aos alunos atuar como sujeitos na elaboração da sua aprendizagem, tendo o professor como facilitador e orientador.?

Nessa perspectiva, a Problematização, exemplo de metodologia ativa, traz a relação entre facilitador e aluno de forma horizontal, proporcionando ao aluno momentos de vivência que o tornam capaz de compreender os vínculos de sua experiência com a prática social global. ${ }^{8}$

Os benefícios da Problematização podem ser visualizados tanto em relação ao discente quanto ao docente. Consoante os supervisores, a metodologia também propiciou uma visão renovada do docente sobre o ato de ensinar e de aprender. Embora a maioria tivesse experiência como instrutor de cursos de auxiliar e de técnico de enfermagem, utilizava a metodologia tradicional, de transmissão de conhecimentos, estando o professor como centro do processo e detentor de todo o conhecimento, diferentemente da metodologia problematizadora. Esta situação é revelada nas falas abaixo.

A gente começou a mudar a mentalidade de professor, nós não estávamos ali pra ser professores, estávamos al i pra dividir saberes, conhecimentos, então a gente não se sentia o dono da classe, nós éramos mais uma pessoa da equipe (S8).

[...] os alunos perceberam que o professor não é aquele que sabe de tudo, não é detentor do saber, que o conhecimento e a experiência deles é muito importante. Como o conhecimento nunca estanca, todos os dias nós estamos adquirindo cada vez mais e isso deu pra perceber bem nessa metodologia (S9).

O contexto desses discursos mostra que o professor tem um grande desafio diante do processo de ensino-aprendizagem, uma vez que ensinar 
exige respeito aos saberes dos educandos. Portanto, torna-se indispensável uma discussão coletiva com perspectiva ampliada para a realidade das classes populares e para o contexto socioeconômico e cultural dos alunos, visto que os saberes são arquitetados no exercício cotidiano, oportunidade em que professor e aluno são sujeitos de uma relação e compartilham de um espaço democrático com possibilidades para a formulação do aprendizado. ${ }^{9}$

Os supervisores entendem, ainda, que a experiência de atuação em um curso como o PROFAE enseja muitas responsabilidades, da mesma forma que havia cobranças, seja pelos alunos, coordenação, gestor municipal, bem como por eles próprios. Esse fato era observado quando necessitavam constantemente revisar temas na literatura, buscando aprofundamento dos conteúdos abordados em sala de aula e no campo. Há, no entanto, a compreensão de que esta experiência possibilitou um crescimento pessoal e profissional significativo.

Nós três nos reuníamos uma hora antes de começar e a gente estudava juntos, então serviu até pra tirar dúvidas porque a gente era muito cobrada, não que a gente não tivesse responsabilidade (S4).

[...] houve um crescimento pra gente enquanto instrutor e, aquilo que a gente aprendeu na escola com o PROFAE, a gente pode também partilhar no ensinar, no conviver com outras escolas, porque quando eu partilho o meu conhecimento todo mundo cresce junto (S6).

Outro fator positivo do curso relatado pelos supervisores refere-se ao material didático, o que contribuiu muito para enriquecer o ensino-aprendizagem, conforme se percebe na fala: $o$ material didático era muito bom, gratuito, bem acessível, de fácil leitura, de fácil compreensão (S2).

O material didático adotado no curso foi composto por um livro - Manual do Técnico e Auxiliar de Enfermagem, que abordava os conteúdos específicos para cada módulo, tendo como foco principal a atuação do técnico em enfermagem na área hospitalar. ${ }^{10}$

No que se refere à formação e capacitação dos egressos, os supervisores confirmaram que houve um avanço dos técnicos de enfermagem após o curso. Esta análise pôde ser apreendida no contato freqüente e seguimento dos egressos nos municípios onde trabalham, sendo ressaltadas a mudança de atitude e a forma mais humanizada dos técnicos durante o cuidado com os pacientes. A transcrição das falas que se seguem denota esta compreensão.

A gente percebe que as atitudes deles mudaram, porque a maioria a gente já conhecia e tinha contato com eles no hospital, e depois do curso, eu mantive um período de contato prolongado com eles novamente, passei uns três meses junto e vi a mudança no dia-a-dia, percebi a diferença, eles estão mais participativos no trabalho, muito mais humanos do que antes (S5).

A mudança de auxiliar pra técnico foi pra eles assim um salto qualitativo. Depois nós observamos isso na prática com eles no hospital, a gente tá vendo que realmente eles estão capacitados. A questão do saber ser e do saber fazer, isso foi uma das coisas bastante notória, eles aprenderam realmente o saber ser e o saber fazer (S3).

Os supervisores levantam ainda algumas diferenças do cuidar que eles perceberam entre os técnicos de enfermagem egressos do PROFAE, comparados aos demais técnicos formados em outros cursos. Segundo os supervisores, os egressos do PROFAE são mais participativos, criativos e têm maior facilidade no trabalho em equipe, ampliando as relações de convivência. Os depoimentos trazem essa percepção.

A diferença é que os outros são tecnicistas e os nossos alunos além da técnica que dominam bem, eles ainda tem essas características a mais de serem participativos, criativos (S10).

[...] outra coisa que faz essa diferenciação entre esses profissionais, é que o aluno do PROFAE está mais ligado ao trabalho em equipe, porque isso foi trabalhado durante todo o curso, sempre em conjunto com os outros colegas, dividindo, partilhando, construindo juntos, agora no campo de trabalho eles se tornaram mais companheiros, mais solidários, mais humanizados (S4).

Outra situação indicada pelos supervisores é o fato de que o curso despertou nos alunos o interesse acadêmico e o aperfeiçoamento futuro, estimulando em alguns o ingresso no curso de graduação em Enfermagem. Além disso, os egressos ficaram motivados para divulgar os resultados de seus trabalhos em eventos científicos. As falas mostram essa realidade: eles viram a necessidade de estudar também. E muitos estão estudando ainda, fazendo especialização em saúde pública, faculdade (S1).

[...] alguns deles, os mais corajosos, despertaram até pra essa questão da pesquisa, fizeram e apresentaram trabalhos na semana da enfermagem (S8).

Estudo realizado com o objetivo de identificar o significado do PROFAE para os alunos revelou que o projeto, além de ter representado a oportunidade de qualificação profissional, proporcionou, também, um estímulo ao aluno para o investimento na vida profissional e pessoal, no que se refere à busca permanente de conhecimento. ${ }^{11} \mathrm{O}$ fato de retornarem para a sala de aula fez com que 
os auxiliares de enfermagem se sentissem competentes, com capacidade de aprender, estimulados pela metodologia que propiciava a visão crítica e reflexiva sobre sua prática.

\section{Desenvolvimento do curso: as dificuldades na visão dos supervisores}

Algumas dificuldades foram vivenciadas no decorrer do CTE do PROFAE/ESP-CE, seja em virtude da descentralização, pouca capacidade técnica das redes de serviço, tempo de execução reduzido em algumas turmas e, até mesmo, por problemas gerenciais do projeto no âmbito nacional. Essas dificuldades foram descritas pelos supervisores que acompanhavam cotidianamente a execução dos cursos no plano local.

Uma das principais dificuldades apontadas pelos enfermeiros foi a falta de organização e planejamento para a execução do curso nos municípios, definidas previamente como contrapartida municipal. As falas a seguir fazem referência a esta situação.

A maior dificuldade que a gente encontrou foi a questão do transporte porque os alunos faziam estágio no hospital regional e a Secretaria de Saúde fornecia uma ambulância, um carro pra levar os alunos, só que isso gerou muitos problemas, porque não tinha ou quando tinha era um carro muito pequeno, eram condições subumanas que eles iam. Uma vez eu cheguei a ver uma ambulância lotada e se acontecesse alguma coisa no percurso? (S6).

Com relação à abertura da Secretaria de Saúde, eu tava revendo aquilo, [...] quando a gente chegava até eles, eles também tinham tudo, entendiam, mas na hora que precisava mesmo não disponibilizavam nada (S2).

Conforme o processo de descentralização dos cursos do PROFAE, os municípios-sede deveriam disponibilizar os enfermeiros do município para seleção e participação nas capacitações, bem como os próprios auxiliares para participar do curso; prover de condições operacionais e financeiras, no que se refere ao apoio logístico, incluindo transporte para visitas e estágios intermunicipais, alimentação, material de consumo, equipamentos de proteção individual, além de garantir instalações físicas mínimas para o adequado desenvolvimento das atividades. Essa dificuldade, entretanto, esteve presente em muitos municípios do Estado do Ceará que sediaram as turmas do PROFAE, no decorrer dos anos de 2002 a 2005.

As parcerias facilitam a superação de obstáculos no processo de trabalho. Em se tratando de um curso profissionalizante para o nível médio, as responsabilidades devem ser compartilhadas entre as instituições formadoras e os municípios, estabelecendo opções gerenciais na condução de questões não apenas pedagógicas, mas também administrativas.

Para a execução descentralizada dos cursos do PROFAE, o projeto estabeleceu parcerias com os gestores do SUS, nas esferas de governo, tendo como intuito a garantia das condições necessárias à implementação das turmas nos municípios. Da mesma forma, articulou-se com os sistemas estaduais responsáveis pela regulação da educação, visando ao reconhecimento do espaço extramuros das escolas como meio passível de desenvolvimento de ações formativas. ${ }^{12}$

Em uma análise dos relatórios de supervisão das Agências Regionais do PROFAE, em 2001, observou-se que os problemas mais freqüentes foram: 1) dificuldades dos alunos com transporte e alimentação, implicando evasão escolar; 2) ausência ou infra-estrutura precária das escolas; e 3) entraves políticos e/ou falta de apoio dos gestores locais. ${ }^{13}$

Outra dificuldade foi relacionada aos campos de estágio para os alunos. O CTE inclui o estágio supervisionado como atividade indispensável ao aprendizado. O objetivo é promover o desenvolvimento de competências (conhecimento, habilidade e atitudes), para atuarem junto ao cliente/paciente com segurança, ética, humanização e respeito, propiciando uma assistência de alta qualidade nas atividades hospitalares e de atenção básica. Além disso, possibilita a integração teoria-prática, situando o aluno diante de ações de promoção, prevenção, controle, recuperação e reabilitação referenciadas nas necessidades de saúde individual e coletiva, determinadas pelo processo gerador de saúde e doença.

Os estágios foram realizados nas unidades de saúde dos municípios-sede de curso, bem como em outros serviços de referência, conforme o desenvolvimento dos módulos, propiciando aos educandos o aprendizado e a vivência profissional em situação real de trabalho.

Os supervisores indicaram que a restrição de campo de estágio, bem como a reduzida disponibilidade daqueles existentes, dificultaram o ensino-aprendizagem, como pode ser observado na seqüência: o único problema que nós tivemos foi só em relação ao campo de estágio, essa foi a dificuldade maior. Os diretores de hospital, às vezes, fechavam um pouquinho, mas graças a Deus elas (coordenadoras pedagógicas) souberam negociar e depois da negocia- 
ção eles viram que a gente tava ali qualificando e que, naquele momento, eles seriam importantes pra melhoria do serviço deles (S10).

Considerando que o objetivo do curso era complementar a qualificação profissional de auxiliares de enfermagem, nos diversos níveis de atenção à saúde, a dificuldade apontada encontra fundamento, pois tais níveis incluem ações primárias, secundárias e terciárias do setor saúde.

Ao se pactuar esta formação junto aos gestores municipais, foi enfatizada a necessidade de realizar o curso in loco, diminuindo ao máximo possível o deslocamento de alunos para outros municípios, principalmente pelo fato de estes estarem vinculados, em sua maioria, às unidades hospitalares municipais na condição de auxiliares de enfermagem. Esta estratégia facilitaria o acesso, diminuiria as possíveis evasões, além de possibilitar o trabalho de conteúdos vivenciados na própria realidade local onde estes alunos estão inseridos. Foram, no entanto, identificados campos de estágio nos municípios com capacidade técnica instalada deficiente, na perspectiva de ações secundárias e terciárias.

Aliado a esta situação, os supervisores levantaram também o período curto de execução para a grande quantidade de conteúdo a ser dispensado aos técnicos. Há, portanto, uma compreensão por parte dos supervisores de que a realização do curso em um período de sete meses, como ocorreu em algumas turmas, restringiu o aprofundamento dos conteúdos, além da prática no campo de estágio.

Teve o tempo que foi curto, foram somente sete meses. Eles questionavam muito, esse curso deveria ser mais prolongado porque foi um corre-corre até por conta do conteúdo. Será que vai dar tempo a gente vê tudo isso? (S3).

[...] a questão da carga horária, da extensão da grade curricular e do tempo, a gente fazia a programação das aulas e eles queriam que a gente aprofundasse o assunto e ninguém tinha condições, porque tinha que preencher aquilo que era determinado pelo PROFAE (S2).

Alguns participantes acreditam que certos conteúdos, como assistência de enfermagem a pacientes críticos e em situações de emergência, por exemplo, deveriam ter sido mais explorados.

Emergência, trabalhar paciente grave, então existe uma chuva de informação tão grande que se você se organizar e pensar o que é emergência, não vamos trabalhar só parada cardíaca, hemorragias. Elas (alunas) tinham uma sede de querer saber mais do politraumatizado, do paciente grave [...] (S6).
No meu ponto de vista, eu acho que tem ser mais tempo pra gente aprofundar mais. Pra eles que estão na área hospitalar, então ela requer assim um tempinho maior exatamente pra que eles saiam dali seguros tanto na parte de conteúdo como na prática (S7).

O CTE do PROFAE/ESP-CE foi planejado para ser executado em 10 meses, tendo uma carga horária semanal de 20 horas, totalizando 750 horas, ao final do curso. As últimas turmas tiveram que ser realizadas em menor tempo, em razão da vigência do contrato. Isto dificultou o aprofundamento de conteúdos, na visão dos supervisores, embora a ESP tenha disponibilizado material complementar para leitura e apreensão destes conteúdos, como uma estratégia de minimizar os problemas.

Apesar das dificuldades apontadas, compreende-se que esta formação deve ser pautada sob a óptica da Política de Educação Permanente, que tem como principais características o fato de ser descentralizadora, ascendente e transdisciplinar, com potencial para desenvolvimento da capacidade de enfrentamento criativo das situações de saúde, independentemente do nível de atenção, bem como melhoria permanente da qualidade do cuidado à saúde, primando pelos conceitos éticos e, principalmente, voltado para a humanização da assistência de enfermagem. ${ }^{14}$

De acordo com os supervisores, o excesso de atividades vivenciadas pelos alunos trabalhadores dificultou o seu ensino-aprendizagem, haja vista que acumularam as atividades profissionais com as educacionais, não sendo liberados em alguns momentos pelos gestores.

A maioria deles trabalhava o dia todo e não tinha nem tempo pra estudar, às vezes, até volto um pouco pra metodologia, eles achavam que "como é que nós vamos estudar pra gente dá aula se a gente não tem tempo?" (S9).

Nós tivemos problema com alguns alunos, tinha uns quatro a cinco que tinha plantão noite sim e noite não e aí no começo do curso tudo bem, quando chegou ao quarto mês eles começaram a dizer que não iam pras aulas, iam ficar alternando (S4).

O MS elaborou o PROFAE com base na necessidade dos inúmeros trabalhadores do sistema de saúde que necessitavam de capacitação, no entanto, deveriam continuar trabalhando. Considerando essa peculiaridade e seguindo as diretrizes do Ministério da Educação, a instituição formadora implementou um curso com atividades teórico-práticas realizadas no período noturno e estágio realizado com uma carga máxima de seis horas diárias no período diurno, quando o aluno/ 
trabalhador deveria ser liberado pelo gestor da unidade, caso estivesse em serviço.

Ao contrário de perceber o trabalho como elemento dificultador da atividade de formação profissional, o curso procurou criar formas e mecanismos de fazê-lo cada vez mais presente no processo de aprendizagem e não criar nenhum mecanismo punitivo, em virtude das dificuldades advindas dessa atividade. Os adultos trabalhadores possuem rica fonte de aprendizagem e formulação de conhecimentos, bem como de socialização e emoções diversas: o seu trabalho. ${ }^{15}$

Outra dificuldade apontada pelos supervisores foi o gerenciamento do auxílio-aluno, criado como uma forma de ajudá-lo nas despesas de deslocamento: eles, coitados, têm mil e uma obrigações com aquilo que eles ganham, com o salário deles e o incentivo foi exatamente a motivação que o PROFAE deu (S8).

A dificuldade que nós enfrentamos foi com relação ao repasse dos alunos, não sei se teve problema com os municípios, porque não foram todos que receberam e isso causou alguns problemas (S6).

Percebe-se que foram apontadas, essencialmente, as dificuldades relacionadas à gerência dos beneficiários, causando insatisfação nos alunos matriculados, que não receberam o auxílio, embora estivessem cursando, ou recebendo-o parcialmente. Os supervisores constataram essa dificuldade, considerando que muitos alunos tinham a expectativa de receber o benefício para ajudar nas despesas. A resolubilidade do problema, entretanto, encontrava-se em uma instância superior, não sendo da competência do nível local nem da instituição formadora.

\section{CONSIDERAÇÕES FINAIS}

A análise do curso, na visão dos supervisores, traz importantes considerações que vão desde a gestão, execução e avaliação da proposta pedagógica da instituição formadora. Observa-se, com arrimo nos discursos, uma avaliação satisfatória em relação ao Curso Técnico de Enfermagem do PROFAE/ESP-CE.

Ficou evidente no relato dos supervisores o fato de que a utilização de uma metodologia ativa apoiada por um material didático adequado, além de facilitar, motivou o ensino-aprendizagem, na medida em que aproximou o aluno da realidade concreta, fazendo com que a formação fosse centrada na realidade, relacionando teoria e prática.

Com suporte no conteúdo apreendido pelos supervisores, o crescimento profissional foi fator freqüentemente ressaltado, reforçando a importância desse tipo de estratégia educacional na formação técnica. Percebe-se, ainda, que o curso propiciou aos técnicos um aprofundamento dos conhecimentos na área da Enfermagem, maiores habilidades técnicas e atitudes efetivas, beneficiando os usuários por eles assistidos.

Ressaltam-se, com efeito, o planejamento e o fortalecimento de parcerias como ferramentas cruciais para a oferta descentralizada de cursos de formação técnica em Enfermagem. Em se tratando de um curso profissionalizante para o nível médio, as responsabilidades compartilhadas entre instituições formadoras e municípios, devem favorecer opções gerenciais na condução de questões não apenas pedagógicas, mas principalmente administrativas.

Considerando o aumento do emprego na saúde e a necessidade de trabalhadores de nível técnico, as escolas que ofertam cursos neste nível, como é o caso da ESP-CE, continuam a desempenhar papel central na elaboração e qualificação desses profissionais, investindo na avaliação dos cursos ofertados, na reestruturação dos currículos, no fortalecimento de parcerias, dentre outras.

Acompanhando este contexto, há a necessidade de investimentos em políticas públicas de formação profissional, não somente na área de Enfermagem, mas também para as demais categorias da saúde, como componente contínuo dos projetos governamentais, contribuindo para a dinamização do mercado de trabalho no setor de saúde e para a melhoria da assistência à população brasileira. Vale ressaltar, ainda, a importância da educação permanente como forma efetiva de assegurar a reflexão e revisão contínua da prática profissional, com o intuito de propiciar mudanças significativas nos processos de trabalho em saúde.

\section{REFERÊNCIAS}

1. Sorio RER. Inovações no campo da gestão de projetos sociais: uma reflexão à luz da experiência do PROFAE. In: Ministério da Saúde (BR). PROFAE: educação profissional em saúde e cidadania. Brasília (DF): MS; 2002. p.17-29.

2. Ministério da Saúde (BR). Edital: projeto de profissionalização dos trabalhadores da área de enfermagem: PROFAE: Estado do Ceará. Brasília (DF): MS; 2001.

3. Minayo MCS, Deslandes SF. Pesquisa social: teoria, método e criatividade. Petrópolis (RJ): Vozes; 2002.

4. Leopardi MT. Metodologia da pesquisa e saúde. $2^{\mathrm{a}}$ ed. Santa Maria (RS): Pallotti; 2002. 
5. Victora, CG, Knauth, DR, Hassen, MNA. Pesquisa qualitativa em saúde: uma introdução ao tema. Porto Alegre (RS): Tomo Editorial; 2000.

6. Bardin, L. Análise de conteúdo. $3^{\mathrm{a}}$ ed. Lisboa (PT): Edições 70; 2004.

7. Fernandes JD, Xavier IM, Ceribelli MIPF, Bianco MHC, Maeda D, Rodrigues MVC. Diretrizes curriculares e estratégias para implantação de uma nova proposta pedagógica. Rev Esc Enferm USP. 2005 Dez.; 39(4):443-49.

8. Berbel NAN. Metodologia da problematização: fundamentos e aplicação. Londrina (PR): UEL; 1999.

9. Freire P. Pedagogia da autonomia: saberes necessários à prática educativa. São Paulo (SP): Paz e Terra; 1996.

10. Lima IL, coordenadora. Manual do técnico e auxiliar de enfermagem. $6^{a}$ ed. Goiânia (GO): ab, 2000.
11. Ferreira MA, Oliveira GRB. Porto IS, Anhorn CG, Castro JBA. O significado do PROFAE segundo os alunos: contribuição para a construção de uma política pública de formação profissional em saúde. Texto Contexto Enferm. 2007 Jul-Set;16(3);445-52.

12. Ministério daSaúde(BR). PROFAE: profissionalização dos trabalhadores da área de enfermagem. Brasília (DF): MS; 2006.

13. Vellozo V. Supervisão no âmbito do PROFAE: notas sobre uma experiência recente. Formação. 2001 Set;1(3):39-48.

14. Ministério da Saúde (BR). Política de educação e desenvolvimento para oSUS: caminhos para a educação permanente em saúde. Brasília (DF): MS; 2004.

15. Aranha, AVS, Frade, ICAS. Educação profissional e básica: integração e omnilateralidade na construção de uma proposta de ensino fundamental para atendentes de enfermagem. Formação. 2001 Set;1(3):25-37. 